\title{
Artículos
}

\section{El Dilema de la enSEŃanZa Religiosa en EURopa: ¿ENSEŃAR A CREER O A CONVIVIR?}

THE DILEMMA OF RELIGIOUS TEACHING IN EUROPE: TEACHING TO BELIEVE OR TO LIVE TOGETHER?

\author{
Flavio Pajer fsc ${ }^{1}$ \\ Turín, Italia
}

\section{RESUMEN}

En el actual contexto europeo, secularizado y plurirreligioso, se han ensayado distintas formas de enseñanza religiosa escolar. En este artículo se presentan la concepción y aplicación de sus principales enfoques en los países de la Unión Europea, al alero de instituciones e iglesias cristianas y de otras confesiones, y muchas veces en conjunto con la autoridad política de cada región. Se sintetiza el variado proceso de profundos cambios de dicha educación según países y credos religiosos, bajo el influjo democrático laico, y la competición entre los

\begin{abstract}
In the current European context, secularized and multi-religious, different forms of religious school education have been tested. This article presents the conception and application of its main approaches in the countries of the European Union, to the eaves of Christian institutions and churches and other confessions, and often in conjunction with the political authority of each region. This summarizes the varied process of profound changes in this education, according to religious countries and creeds, under the secular democratic influence, and competition between
\end{abstract}

1 Hermano de La Salle, profesor emérito del Institut Catholique (Paris y Abiyán) y de la Universidad Pontificia Salesiana (Roma).fpajer@lasalle.org 
Flavio Pajer fsc | El dilema de la enseñanza religiosa en Europa: ienseñar a CREER O A CONVIVIR?

Estados frente a las Iglesias y otras religiones. Se exponen las estrategias jurídicas y pedagógicas de las Iglesias cristianas ante los cambios culturales más amplios, su evolución y posibles desarrollos; y se concluye con una propuesta fundada y prudente frente a la compleja situación.

\section{Palabras clave}

Europa, Estado-Iglesias, educación religiosa escolar, libertad religiosa, políticas educativas.
States in the eyes of the Churches and other religions. The legal and pedagogical strategies of the Christian Churches are exposed to the broader cultural changes, their evolution and possible developments; and it concludes with a well-founded and prudent proposal in the face of the complex situation.

\section{KEY WORDS}

Europe, State-Churches, school religious education, religious liberty, education politics. 


\section{INTRODUCCIÓN}

Europa, respecto del resto del planeta, es el área geográfica donde:

- se concentra un número inigualado de fronteras nacionales y de barreras lingüísticas (en 27 países miembros de la Unión Europea se hablan 17 lenguas oficiales e innumerables dialectos);

- unas trescientas culturas minoritarias regionales conviven con las grandes culturas seculares: la cultura latino-mediterránea al sur, la anglosajona y escandinava al norte, la eslavo-bizantina al este;

- la geografía religiosa depende de la huella cultural y ética -antes polémica, hoy de tendencia ecuménica- de las tres tradiciones confesionales cristianas (Stagi, 2017) y sus relaciones con las políticas de los respectivos Estados (Robbers, 2004), caracterizadas por sus diferentes expectativas y estrategias hacia la escuela pública.

- la secularización de la modernidad tardía erosionó a los creyentes en magnitud preocupante, pues cada vez más se habla de descenso (al menos estadístico) de la Europa cristiana, de Europa "enferma de cristianismo", de "Europa posreligiosa".

- las regulaciones de la educación primaria, secundaria y superior dependen todavía de las autoridades nacionales, y en ciertos casos -como en Inglaterra, Alemania, Bélgica, Suiza- de autoridades educativas subregionales.

\section{Por un mapa razonado de las enseñanzas RELIGIOSAS}

La adhesión de Estados a la Unión Europea provocó el creciente interés de las Iglesias nacionales por aumentar las relaciones de conocimiento mutuo. Las conferencias episcopales nacionales católicas formaron un Consejo Europeo (CCEE), al igual que las 
Flavio Pajer fsc | El dilema de la enseñanza religiosa en Europa: ienseñar a CREER O A CONVIVIR?

Iglesias protestantes (KEK). Al caer el muro de Berlín (1989), a las Iglesias occidentales se agregaron las del Este europeo, incluidas las comunidades ortodoxas liberadas de la tiranía soviética después de décadas. Muchas facultades teológicas de varias confesiones comenzaron a trabajar en red (Chizzoniti, 2006), en paralelo al "proceso de Bolonia" (1998) realizado por el Consejo de Europa para homologar los estudios en las universidades estatales. Numerosas reformas escolares nacionales han asumido los progresos de las ciencias pedagógicas y didácticas, incluyendo la enseñanza religiosa, que pudo confrontarse con modelos (confesionales o no) practicados en el continente. Las escuelas católicas ${ }^{2}$ formaron el Comité Europeo para la Enseñanza Católica (CEEC), que tiene entre sus estrategias prioritarias la promoción e innovación de la cultura religiosa en los planes de estudio. Desde 1951 hay un Equipo Europeo de Catequetas (EEC), que estudiaba inicialmente también la enseńanza religiosa escolar, pero en 1984 surgió el Foro Europeo para la Enseñanza Religiosa, al distinguirse su naturaleza y competencias -ya desde los ańos 1970-80 - respecto de la catequesis eclesial. Paralelamente, las Iglesias protestantes establecidas con base nacional multiplicaron grupos transnacionales de colaboración europea.

El cruce de tantas iniciativas convergentes sobre la escuela y sus prácticas jurídicas y didácticas en religión ha producido mapas cognoscitivos y comparativos sobre los esquemas de enseñanza religiosa existentes en los sistemas educativos nacionales. Son informaciones y lecturas que necesitan actualización constante debido a las frecuentes reformas escolares estatales, a las revisiones de concordatos, a las normas jurídicas cada vez más exigentes sobre libertad religiosa, a las nuevas directrices en la formación de docentes, al avance de la

2 Acogen en promedio el $20 \%$ de la población escolar primaria y secundaria del continente. Los países con mayor porcentaje son Bélgica y Holanda (60\%-70\% de la Enseñanza libre), España (25\% de la Enseñanza concertada), Francia (18\% de la Enseñanza bajo contrato de asociación), Inglaterra y Gales (10\% de las Escuelas católicas), Austria (5,8\% de las Escuelas católicas), Italia (3,8\% de las Escuelas paritarias), Alemania (3\% de las Escuelas católicas). 
secularización de la cultura, y a la creciente diversidad religiosa de los escolares por los flujos de migrantes.

En la producción bibliográfica hay cinco enfoques:

1. Enfoque descriptivo: numerosos informes describen la enseñanza religiosa país por país, considerando sus componentes estructurales: su base legal, su régimen jurídico (obligatorio, optativo, facultativo, extracurricular), las disciplinas contenidas, la presencia de alguna materia alternativa, la formación cultural y el estatus jurídico-económico del docente (Pajer, 1991; Conferencia Episcopal Italiana, 2007; Kuyk y otros, 2007; Catterin, 2013): Otros informes presentan solo algunos grupos más significativos de sistemas educativos (Genre-Pajer, 2005; Willaime-Mathieu, 2005; Pépin, 2009; Messner, 2010; Rusconi, 2012). Estos informes descriptivos retratan los desarrollos recientes y las situaciones de los últimos 30 años.

2. Enfoque pedagógico: la pedagogía religiosa inglesa (Grimmitt, 2000; Jackson, 2014) distingue tres modelos de enseñanza religiosa (al interior del acerca del desde la religión) según la postura posible del docente y del estudiante frente a la "religión". Esta tipología también se aplica útilmente para distinguir los modelos de enseñanza religiosa de diferentes sistemas nacionales europeos:

a) enseñar/aprender al interior de la fe o de la religión, en el caso de la educación a la fe en la catequesis escolar y en la pastoral estudiantil. La relación educativa ocurre entre educadorcreyente y estudiante-educando a la fe, generalmente en escuelas confesionales y públicas en sistemas con régimen concordatario, donde la enseñanza religiosa se debe dejar a la libre elección de la familia tanto del estudiante de primaria como el de secundaria.

b) enseñar/aprender acerca de la religión o de las religiones, en la enseńanza objetiva de la historia, de los textos, de las doctrinas, del impacto social de una o más religiones. El estudio de la religión, incluida la religión mayoritaria del país, es similar 
al de otras materias curriculares como historia, filosofía, derecho. El docente, formado en instituciones del Estado, tiene competencia científica sobre la materia y, al enseñarla, respeta las identidades religiosas de los estudiantes, evitando, especialmente al hacer comparaciones, privilegiar una religión sobre otras.

c) enseñar/aprender desde una(s) religión(es), en el caso de educación de los valores de la persona y de la sociedad, tomados del inmenso capital ético-simbólico de una o más tradiciones religiosas, entendidas como "escuelas" de experiencia personal y comunitaria, de sentido de la vida, de pensamiento teológico y simbólico, de normas reguladoras del comportamiento. Las religiones son y permanecen como auténticas minas de patrimonio cultural y de valores que la escuela puede y debe ofrecer a los estudiantes, cualquiera sea su pertenencia a una Iglesia o a ninguna.

3. Enfoque epistemológico: su punto de partida es la base epistemológica del saber religioso que promueven (Pajer en Domingo Moratalla, 2006, pp. 143-169). Los docentes conservan como fundamento científico las ciencias teológicas de su tradición confesional (católica, ortodoxa, evangélica) o de las religiones minoritarias difundidas en el territorio europeo (islam, budismo, hinduismo...). Otras enseñanzas, incluidas las reguladas por concordatos de los años 80-90 del siglo $\mathrm{XX}$, adoptan un sistema mixto: integran, con las ciencias teológicas, lenguajes y métodos de las ciencias positivas transconfesionales de las religiones, para armonizar la cultura religiosa con los demás saberes de las disciplinas curriculares. Otras enseñanzas, en contextos sociales muy secularizados, se fundan solo en las ciencias de la religión, sin excluir la teología (que es saber científico, en sentido pregalileano), pero leen los contenidos según la propia epistemología laica.

4. Enfoque legal-jurídico: los juristas distinguen los modelos de enseñanza religiosa según los documentos jurídicos internacionales (primero, 
la Convención Europea de Derechos Humanos) que los Estados de la Unión Europea deben respetar. Hay tres grupos de países:

a) países sin enseñanza religiosa como Francia, Eslovenia, la República Checa, Hungría, donde se permiten cursos optativos de religión, vespertinos y fuera del horario escolar;

b) países con enseñanza no confesional, controlada por el Estado, con programas curriculares y evaluación de la disciplina; así todo el norte europeo de mayoría anglicana y luterana: hay Educación religiosa multifé o Religiones y concepciones del mundo en Inglaterra; Historia del cristianismo luterano o de las religiones en general en Dinamarca, Suecia, Letonia; Ética y corrientes espirituales en Holanda...;

c) países con enseñanza confesional de la religión; especialmente los de mayoría católica (una decena de países concordatarios) y ortodoxa (los países poscomunistas del Este europeo, más Grecia y Chipre). Las respectivas Iglesias controlan los programas y la formación docente, sostenidos económicamente por el Estado. Son optativos por ser de gestión confesional (pero con finalidad específicamente escolar, a diferencia de la catequesis parroquial). Grupos religiosos minoritarios (judíos, musulmanes) pueden proponer programas histórico-culturales (no proselitistas) aun en la escuela pública.

5. Enfoque sistémico: es el que he intentado construir con base sociológica y también jurídico-pedagógica subdividiendo los esquemas de enseñanza religiosa europeos según los "tres paradigmas": políticoconcordatario, académico-curricular, ético-valórico (ver Pajer, 2015). La utilidad de este enfoque consiste en una mirada sinóptica que toma en cuenta tanto los elementos estructurales constitutivos y calificantes internos a cada paradigma, cuanto la relativa semejanza/ desemejanza entre factores similares de paradigmas vecinos, y también cierto deslizamiento temporal que mueve al primer paradigma a evolucionar hacia el segundo, y este hacia el tercero. 
Flavio Pajer fsc | El dilema de la enseñanza religiosa en Europa: ienseñar a CREER O A CONVIVIR?

\section{UNA REVOLUCIÓN EN PROGRESO, UN ESCENARIO PROBLEMÁTICO}

Una revolución silenciosa ocurre hace años en las aulas de Europa: los cursos de Religión están cambiando contenidos, métodos, didáctica, pero, más significativo, está cambiando de raíz su razón de ser en la escuela pública. Esta asignatura se legitima cada vez menos por razones de interés religioso o confesional, cada vez más lo hace por su relevancia cultural, cívica, ética. Se han interesado por esta asignatura, antes gestionados casi siempre por las autoridades religiosas locales, organismos laicos supranacionales: la Comisión de la Unión Europea, la Asamblea Parlamentaria del Consejo de Europa, la UNESCO y la $\mathrm{OSCE}^{3}$ (Parisi, 2005). En algunos Estados el Ministerio de Instrucción Pública solicita medidas para potenciar la consistencia de los saberes y de las competencias relacionadas con el fenómeno religioso. Las tradiciones religiosas mayoritarias de ciertos Estados siguen teniendo voz en el tema, pero las minorías, incluidas organizaciones filosóficas o humanísticas, también son legítimas y escuchadas. Ya no son novedad en el currículum de millones de escolares y estudiantes europeos los cursos sobre el islam y otras religiones de reciente inmigración, sobre humanismos no religiosos y sobre sistemas éticos no confesionales. Los docentes de Religión todavía pueden actuar en ciertas situaciones como representantes de su comunidad de pertenencia, pero cada vez más el ejercicio de su rol profesional público está vinculado al reconocimiento académico y jurídico del Estado. En el aula nunca se les pedía una fría neutralidad, pero se impone cada vez más una ética docente imparcial, sin discriminación injusta, porque también a los menores se les reconocen derechos, y "el primero de estos derechos es la libertad de conciencia y de religión”.4.

3 Organización para la Seguridad y la Cooperación en Europa (N. del T.).

4 Ver el reciente documento de la Comisión Teológica Internacional, La libertad religiosa para el bien de todos. Enfoque teológico a los desafios contemporáneos, marzo 2019 (se señala dirección web del texto en italiano a falta de la versión en espańol - N. del T.): http://www.vatican.va/ roman_curia/congregations/cfaith/cti_documents/rc_cti_20190426_liberta-religiosa_it.html 
En pocos años, en Europa el binomio religión-escuela se ha convertido en objeto privilegiado de investigaciones empíricas, de periódicos monitoreos, de lecturas multidisciplinarias en centros académicos, de revistas universitarias, de organismos públicos y privados, confesionales y estatales 5 . Cuando un país debe escoger entre diversos sistemas de enseńanza religiosa, no es raro que se pida la decisión ya no a la vía diplomática entre cumbres institucionales, sino en votación a los ciudadanos o según el resultado de experiencias objetivas. Y que el hecho religioso sea hoy percibido notablemente con sensibilidad o susceptibilidad distinta que en el pasado, lo demuestra el cuidado ya generalizado por regular también jurídicamente el recurso a los símbolos religiosos en las aulas, en el decorado de los espacios públicos y en la vestimenta de alumnos y docentes, en las costumbres alimentarias y en el ritmo del calendario semanal. La religión sale de los templos y de las aulas para entrar incluso a los tribunales, llamados a superar abusos y discriminaciones. Si por siglos la religión era la solución a tantos problemas (aun sociales), hoy ella se ha convertido en problema.

Para sintetizar esta mirada panorámica a una Europa en movimiento, consideremos los siguientes rasgos:

- está cambiando rapidamente el perfil sociorreligioso de la población escolar, y las experiencias religiosas efectivamente vividas y vivibles por los jóvenes se hacen cada vez más escasas; el itinerario catequístico y sacramental cumplido en la comunidad eclesial tiende a terminar para gran parte de los bautizados con la preadolescencia.

5 Entre las revistas académicas que han dedicado números monográficos o una sección temática a la enseñanza religiosa europea, citamos: Bordón (Revista de la Sociedad Española de Pedagogía), LVII, 2006, 4-5, pp. 451-710; Numen (NL), Lv, 2008, 2-3, pp. 123-334; Studi e Materiali di Storia delle Religioni, Lxxv, 2009, 2, 371-563; Religioni e Società, xxv, 2010, 3, pp. 9-99; Rivista di Storia del Cristianesimo, Ix, 2012, 1-122; Historia Religionum, IV, 2012, 11-121; Comparative Sociology, XV, 2016, 4, pp. 439-484. 
- la morfología del fenómeno religioso y "espiritual" actual es mucho más amplia y variada que la del universo religioso codificado en la tradición cristiana occidental, y resulta insuficiente el léxico teológico cristiano para describir el multiforme fenómeno religioso de hoy; el horizonte del pensamiento y de la acción de las Iglesias cristianas del siglo XXI, según los teólogos del pluralismo religioso (Panikkar, Geffré, Dupuis, Küng) ya no es el ateísmo sino el pluralismo religioso. La fe cristiana no basta como base de la cultura religiosa europea.

- en tiempo de eclipse de la ética y en una sociedad secular que entiende ser "éticamente neutra", también la demanda educativa que muchas familias dirigen a la escuela se ha mudado de las clásicas "verdades catequísticas y normas morales" a los principios éticos y de derechos humanos presentados como de racionalidad antropológica más que como verdad revelada o de un magisterio oficial.

- con las ciencias teológicas valorativas, que legitimaban las enseńanzas confesionales, las ciencias de la religión, históricas, o empíricas, o hermenéuticas, pueden justificar la investigación religiosa, dialogar con los demás saberes escolares y en primer lugar con la visión también teológica de los problemas, sin entrar por eso en conflicto con las Iglesias oficiales o con la fe de las personas.

- los saberes escolares están de hecho bajo el primado de las disciplinas científicas en detrimento de las humanísticas, más afines a los códigos simbólico-religiosos, por lo cual la enseñanza escolar tiende a marginar o callar el insuprimible problema del sentido, "verdadero código genético de la sociedad" (N. Luhmann), que permanece ahora como problema laico, común a todo alumno, antes que ser un problema religioso y menos todavía uno sobre el cual una sola confesión religiosa pueda reivindicar competencia en una sociedad multicultural. 
- en todas las sociedades europeas la religión judeocristiana, y no solo ella, está entrecruzada en la historia y en la cultura, y encuentra expresión en la poesía, la música y las artes. Promover competencia cultural en los estudiantes requiere una confrontación con la propia herencia religiosa, con otras tradiciones religiosas y con los sistemas de sentido no religiosos.

- en las imágenes y símbolos de las religiones las personas encuentran lenguaje para expresar sus experiencias, sus preguntas y su comprensión sobre el comienzo y fin de la vida, para decir la felicidad y el sufrimiento, el sentido y el sinsentido, la alegría y el dolor, el bien y el mal. Exigir competencia cultural personal a los estudiantes requiere afrontar las afirmaciones existenciales fundamentales de las religiones.

- la pedagogía escolar, que siempre adopta las metodologías del enfoque intercultural confirma que para los jóvenes de hoy la construcción de sentido y de identidad religiosa no resulta tanto del aislamiento en grupos homogéneos, sino del contacto y del diálogo interactivo y constructivo con las diferencias religiosas y culturales.

\section{Poderes civiles y autoridades religiosas en COMPETENCIA}

Un problema emergente en el panorama europeo es el redimensionamiento de la cuota de poder de las Iglesias para regular la enseñanza religiosa en una escuela que, con el aumento de la heterogeneidad religiosa de la sociedad, debe diversificar su oferta no tanto en cantidad de nuevos cursos confesionales según las múltiples pertenencias de los alumnos, cuanto en el nuevo perfil cualitativo -o en un nuevo canon- de la enseñanza religiosa. Por hipótesis, piense en una enseñanza religiosa que considere al alumno ante todo en su condición de persona y no en su eventual afiliación confesional; que le ofrezca instrumentos válidos para comprender el patrimonio simbólico y ético de las religiones 
Flavio Pajer fsc | El dilema de la enseñanza religiosa en Europa: ienseñar a CREER O A CONVIVIR?

humanas; que al apropiarse de los elementos históricos, culturales y éticos de su propia tradición religiosa, aprenda también a comprender y a dialogar con quienes tienen otra fe o ninguna. Una enseñanza religiosa así -calificable como el mínimo común denominador de la alfabetización religiosa actual- precede a la eventual iniciación confesional esperada por derecho en la comunidad de pertenencia. Y compete a la autoridad escolar proveer y gestionar currículos de perfil no confesional, partiendo de la presuposición epistemológica de que la escuela propone saberes y competencias sobre las religiones, lo cual no coincide -ni se opone en principio-con educar en o a la fe. Si las Iglesias cogestionan con la autoridad pública una u otra forma de enseñanza religiosa propuesta en régimen opcional, no tienen el monopolio y, en algunos casos, pierden también el derecho a veto sobre las orientaciones de la política educativa nacional o regional.

Sin duda, la Europa de la educación escolar ve atenuarse hoy aquel pacto entre poder civil y religioso, estipulado cuando las comunidades religiosas eran (o se suponía que fuesen) coextensivas con las respectivas sociedades civiles. No es efecto solo de la secularización de ayer ni de la post-secularización de hoy. Han intervenido en este campo otros actores, capaces de influir en las opciones de política educativa: por una parte, la presencia de otras religiones que llegaron con la inmigración, portadoras de demandas explícitas de formación religiosa y doctrinal; por otra, las instancias laicas de la Unión Europea y de otros organismos supranacionales, con títulos y competencia para intervenir en cuestiones de seguridad urbana, de integración social, de política educativa, sin excluir la enseñanza religiosa; y también el poder académico de la comunidad científica (facultades estatales de teología y de ciencias religiosas, centros de investigación interreligiosa), capaz de orientar a las nuevas generaciones de docentes mediante la enseñanza institucional, y de influir en la opinión pública mediante la divulgación mediática.

Las instituciones europeas, particularmente el Consejo de Europa, desde los años 80 pidieron vigilar y prevenir ciertos fenómenos de xenofobia y de intolerancia religiosa, presentes en medida preocupante 
en regiones del continente. Surgieron directrices para disciplinar actividades abusivas de las sectas, para hacer respetar los derechos culturales y religiosos de las minorías, para fomentar la educación para la democracia, la nueva ciudadanía, los derechos humanos, el diálogo intercultural. Así no podía faltar una atención especial al factor religioso como "polo sensible" acerca del cual invitar a los sistemas escolares nacionales a invertir recursos cognoscitivos y educativos.

Ese alto interés por la gestión de lo religioso cuestiona la competencia de las autoridades religiosas locales que, en cada Estado, cogestionan la enseñanza religiosa en los respectivos sistemas educativos. Pero las Iglesias y las demás organizaciones religiosas ya no pueden quedar indiferentes ante las intervenciones urgentes y sistemáticas de tal “magisterio laico". Cabe la pregunta: ¿qué estrategias adoptan las confesiones cristianas y las religiones para negociar su permanencia o ingreso a las aulas?, ¡cómo reaccionan ante los imperativos democráticos de respetar la libertad religiosa, de promover la ciudadanía, de defender la laicidad?, ¿cómo se respetan y promueven en las escuelas europeas de hoy los derechos de la persona, del creyente? Si ya se advierte la necesidad de discutir el concepto de "religión" para adecuarlo a las heterogéneas experiencias de espiritualidad, de interpretaciones extrateológicas, ¿quién tendrá competencia para redefinir las fronteras de tal concepto? ¿Corresponderá a la autoridad académica de las ciencias de la religión entrar en el debate?

\section{Las estrategias educativas de las Iglesias CRISTIANAS}

La "política educativa escolar” de la Iglesia Católica es fácil localizarla en las últimas revisiones concordatarias y en los documentos episcopales sobre enseñanza religiosa escolar.

4.1. Las revisiones concordatarias posconciliares redefinen el perfil y el rol de la enseñanza religiosa escolar, abandonando la visión del catecismo para adoptar el enfoque educativo público al que la escuela pertenece. 
Flavio Pajer fsc | El dilema de la enseñanza religiosa en Europa: ienseñar a CREER O A CONVIVIR?

Esto, con una doble ventaja: acreditar la asignatura de Religión en un ambiente escolar actualmente autónomo y laico, y garantizarse la adhesión de muchos alumnos manifiestamente hastiados del modelo doctrinal y parenético precedente. Una enseñanza informativa y crítica sobre la religión católica, y además educación en la fe y para la fe, permite un acceso a los cursos de Religión menos selectivo y discriminante, ya que, en algunos casos, tienen derecho a inscribirse también alumnos de otras confesiones o no creyentes.

En los países pluralistas de Europa occidental la Iglesia Católica rediseńó la figura concordataria de su enseñanza religiosa ahora como descatequización y plena escolarización. En cambio, en los países de la Europa poscomunista, donde apenas hubo en los años 90 condiciones favorables a relaciones diplomáticas normales y colaborativas entre Estado e Iglesias, se creó un perfil paracatequístico (Barberini, 2004; Pajer, 2005). Pronto se activaron cursos confesionales de religión católica en Polonia, Lituania, Hungría, República Checa, Eslovaquia, Eslovenia, Croacia. Otras Iglesias cristianas hicieron intercambiables la catequesis y la enseńanza religiosa escolar confesional: las comunidades evangélicas gestionan sus cursos confesionales en República Checa, Croacia, Letonia, Lituania, Hungría. Los cursos católicos y los evangélicos tienen siempre un carácter opcional, independientemente del hecho de que una Iglesia sea mayoritaria o no en cada país.

En lo referente a la confesionalidad de la enseñanza católica en los países del Este, son explícitos los enunciados en los acuerdos suscritos, que documentan cómo las autoridades diplomáticas vaticanas y las jerarquías locales mantienen su tozuda defensa identitaria del propio patrimonio, considerando el largo tiempo en que las comunidades cristianas locales carecieron de la libertad religiosa más elemental. Las sociedades nacionales del Este apenas "descongeladas", durante la década de los años 90, sentían la urgente necesidad de recuperar la dignidad y la identidad cultural más que medirse democráticamente con la diversidad. En los últimos veinte años, también católicos de esos países han elevado voces que auspician una apertura más democrática hacia las demás confesiones y religiones, y hacia los agnósticos. La 
legislación reciente de esos países respeta la "libertad de no creer", y tolera visiones humanísticas, creencias filosóficas y ateas.

4.2. Otras fuentes preciosas para monitorear la evolución de la postura católica sobre la religión en la escuela son los documentos de las conferencias episcopales nacionales sobre el asunto. Los documentos van desde el género jurídico-normativo hasta el parenético, de la propuesta de programas a intervenciones en debates públicos. Me limito a algunos casos ejemplares.

En Alemania se ha señalado el documento sobre el "potencial formativo de la enseñanza de la religión”. En este, los obispos han reconfirmado -de manera inequívoca- mantener una enseñanza religiosa distinta según las confesiones, como prevé la Constitución (art.7); además toman posición sobre muchos nodos problemáticos surgidos en los ańos siguientes a la caída del muro de Berlín, en pleno proceso de unificación territorial y política: el cambio de sensibilidad cultural de toda la sociedad, al mismo tiempo menos practicante, la presencia creciente de estudiantes extranjeros de otras religiones o sin pertenencia, el debilitamiento de las iniciativas ecuménicas, que eran bastante prometedoras pocos años atrás. Sorprende que, ante tamaños problemas, el documento termine proponiendo un par de orientaciones operativas muy modestas: la apertura de cursos también a no católicos que los pidan, y aumentar la atención pedagógica a cada contexto sociorreligioso. Ninguna revisión profunda al perfil epistemológico y pedagógico de la disciplina como se hizo más de veinte años antes (1974) con el famoso decreto del Sínodo de obispos sobre la enseñanza de la religión ${ }^{7}$, al punto que también un notable pedagogo alemán debió admitir que "hasta ahora la toma de posición unilateral de los obispos ha tenido un efecto más bien

6 Su nombre completo es Die Deutschen Bischöfe, Die Bildende Kraft des Religionsunterricht. Zur Konfessionalität des katholischen Religionsunterrichts, Bonn, Sekretariat des Deutschen Bischofskonferenz, 1996.

7 Der Religionsunterricht in der Schule, in L. Bertsch et al., Gemeinsame Synode der Bistümer und der Bundesrepublik Deutschland, Offizielle Gesamtausgabe, Freiburg/Br. 1978, I, pp. 113-152. 
Flavio Pajer fsc | El dilema de la enseñanza religiosa en Europa: ienseñar a CREER O A CONVIVIR?

paralizante sobre los debates de la pedagogía de la religión", tesis auspiciadora de una concepción y de una praxis alternativas a la enseñanza monoconfesional (Porzelt, 2014). Efectivamente, frente a la progresiva pérdida de relevancia de las confesiones, de la religión y de las tradiciones en general, se hace cada vez más difícil mantener el clásico sistema de la triple confesionalidad (Trias): de la doctrina, del alumno y del docente. Si tal sistema, de jure, parece persistir, de facto ya está superado por difundidas prácticas de enseñanza biconfesional e interconfesional, y quizá también interreligiosa.

En Austria, las condiciones socioculturales y la organización del sistema educativo permiten todavía a la Iglesia Católica romana tener el rol de líder de la didáctica religiosa en las escuelas. Sus responsables reconocen aún hoy que la enseñanza religiosa "sigue siendo la única -ipero quizás la última!- posibilidad que permite a la Iglesia tener contacto con los jóvenes a escala más o menos extensa" (efectivamente, el 78\% de los estudiantes católicos frecuenta el curso de Religión en las escuelas públicas y otro $6 \%$ en las escuelas católicas). Otras trece comunidades religiosasse disputan fracciones menores de la población escolar; en más de cien escuelas rige la obligación de impartir ética no confesional. Las escuelas católicas no niegan ya la inscripción a los no católicos, pero les ofrecen la oportunidad de frecuentar un curso especial sobre su propia religión. La enseñanza de la Religión católica en el sistema público se basa en los fines y contenidos doctrinales controlados por las oficinas competentes de la jerarquía, pero la demanda educativa de las familias, y en particular la de los estudiantes, desvían los contenidos hacia temas antropológicos y sociales que atañen a la educación ético-moral y ecológico-espiritual. Esta última tendencia anima a alumnos de otras pertenencias a frecuentar el curso católico amparado de presiones proselitistas. Las Iglesias cristianas fundaron juntas un centro superior de pedagogía religiosa para preparar docentes y expertos competentes sobre las distintas tradiciones cristianas y sobre los grandes monoteísmos.

En Bélgica, la diversidad religiosa -hoy muy avanzada por el alto número de laicos o "librepensadores" (así se declara más de 20\% de los 
adultos) - se acompaña, como es sabido, por la diversidad lingüística de las tres comunidades federadas, por la diversidad administrativa (la escuela es de competencia de las comunidades lingüísticas), por la consistencia singular de las escuelas libres subvencionadas respecto del menor número de escuelas estatales. La Iglesia Católica, desde los años 70 , en plena etapa de la secularización en masa, ha advertido la necesidad de jugar una nueva carta en la enseñanza de la religión: apuntar a "humanizar" al alumno, al mismo tiempo que lo insta a interrogarse sobre el problema religioso. De estos presupuestos nacieron los nuevos programas de Religión, renovados varias veces para adecuarlos tanto a las tendencias cambiantes de la cultura juvenil, al escenario social de la nueva religiosidad, a los objetivos educativos de la asignatura, como a los métodos del trabajo disciplinar. Más determinante ha sido otro factor: la presencia cada vez mayor de alumnos no católicos en la red de escuelas libres católicas ha movido a los responsables a innovar programas de "cultura religiosa", armonizándolos con las necesidades educativas de cursos cada vez más heterogéneos culturalmente; al hacerlo han ideado procesos de alfabetización religiosa preconfesional, a costa de dejar inexplorado parte del patrimonio cristiano, que, presumiblemente, también quedaría desatendido a falta de prerrequisitos antropológicos. Esto, sin embargo, con la decepción de las autoridades institucionales al ver que se agota "lo específico cristiano", que era la razón de ser del compromiso de siglos de la Iglesia en la escuela. El resultado de estos años ha sido que los cinco cursos confesionales optativos fueron sustituidos en 2017 por un curso único obligatorio de dos horas semanales, llamado "Curso de Filosofía y Ciudadanía". Parecida opción hizo Luxemburgo en 2016, al eliminar, por ser cada vez menos frecuentados, los anteriores cursos optativos católico y protestante, para sustituirlos por un curso curricular de introducción a los problemas existenciales y éticos llamado "Vida y sociedad".

En España concordataria, el campo de batalla donde se han enfrentado la Iglesia y el Estado es la Educación para la ciudadanía y los Derechos Humanos, introducido por el gobierno socialista como 
Flavio Pajer foc | El dilema de la enseñanza religiosa en Europa: ienseñar a CREER O A CONVIVIR?

materia obligatoria en la Ley Orgánica Educativa de reforma (LOE, 2006). La objeción de fondo puesta por los partidos de derecha, a los que se ha asociado la jerarquía católica, es que con tal disciplina el Estado pretende constituir un Estado ético y apropiarse de la educación moral de los ciudadanos menores. Los opositores reivindican el respeto al artículo 27,3 de la Constitución, apoyándose en la Carta de los Derechos Fundamentales de la Unión Europea (art. 14,3) y en la Declaración Universal de los Derechos Humanos (art. 26,3). En particular, la Conferencia Episcopal objetó que la nueva materia sobrepasaba los límites de una presentación objetiva del ordenamiento constitucional y de las declaraciones universales de derechos, para adentrarse con tonos y juicios abusivamente asertivos en temas morales muy controvertidos, en una óptica-lamentan los obispos-claramente ajena a la doctrina social de la Iglesia.

Sería excesivo presentar más casos nacionales, considerando además que la posición de cada conferencia episcopal va ligada al propio contexto jurídico. Es distinta una enseńanza religiosa con base legal en la Constitución (Alemania), respecto de las enseñanzas de tipo concordatario (Italia, Espańa, Malta), o de la gestionada por la autoridad escolar (Inglaterra), o de la enseñanza laica del hecho religioso en las demás disciplinas (Francia). La variedad perfiles jurídicos origina una especificidad de motivaciones pedagógicas y de tratamiento didáctico. En otras palabras: no hay "una" enseñanza europea de la religión católica, comparable a la singularidad vinculante del catecismo católico. Puede parecer paradójico, pero las mismas motivaciones teológicas adoptadas por las conferencias episcopales europeas para legitimar la enseñanza religiosa escolar son necesariamente divergentes, al tener que razonar en contextos sociales y eclesiales que no son fotocopias unos de otros.

4.3. No es superfluo aludir a las estrategias de las otras Iglesias cristianas en el mundo escolar. Conozcamos la herencia que el protestantismo europeo ha dejado a la conciencia moderna: un sentido de la Escritura, una espiritualidad bíblica, el gusto de la libertad responsable, una propensión a la democracia y a la laicidad, una preocupación ética 
ante la actividad económica y en la búsqueda de la justicia. El afán educativo de la escuela, en los países de mayoría evangélica o luterana, muestra positivamente estas opciones: la escuela, antes que ser eventualmente concebida como lugar para impartir cursos de religión, es una institución que por sí misma debe orientarse a conseguir valores de base "laicos", de democracia cívica y de honestidad intelectual, de libertad de conciencia y de libertad de pensamiento, de espíritu crítico y de sana eficiencia.

También hoy, ante la tarea histórica de construir una Europa unida,

"las Iglesias protestantes se preocupan menos de la Europa religiosa que de la Europa a secas, como se está construyendo en Bruselas ${ }^{8}$ y en Estrasburgo'. Las intervenciones de las Iglesias protestantes interpelan a las instancias europeas sobre la Europa social, sobre la política de inmigración, sobre la falta de democracia... Son intervenciones de naturaleza ética, a menudo críticas sobre cómo se pretende construir Europa prescindiendo de 'exigencias evangélicas', de protección a los pobres o a los extranjeros. Lejos de reclamar por el contexto secularizado y pluralista de las sociedades en que viven, las Iglesias protestantes tienden a desarrollar un ministerio de vigilancia ética" (J.P. Willaime, del manuscrito de una conferencia, París, 2016).

En Alemania las Iglesias evangélicas, después del debate sobre la reunificación del país, se han pronunciado sobre la enseñanza religiosa en el documento Identidad y comprensión. Posición y prospectiva de una enseñanza de la religión en el pluralismo (EKD, 1994). En Francia, la Federación Protestante ha intervenido varias veces respecto de la "cultura religiosa en la escuela", ante acontecimientos nacionales o debates públicos sobre la laicidad del Estado y de la escuela. Los protestantes promueven repatriar la cultura religiosa en la cultura escolar en clave histórica y sociológica, no confesional ni moral. En

8 Sede en Bélgica de la Unión Europea (N. del T.).

9 Sede en Francia del Consejo de Europa (N. del T.). 
Flavio Pajer foc | El dilema de la enseñanza religiosa en Europa: ienseñar a CREER O A CONVIVIR?

un documento de síntesis, corroboran algunos puntos capitales de su posición: la ignorancia de otras religiones puede producir intolerancia y prejuicios, así como un mal conocimiento de la propia religión puede llevar al integrismo y el oscurantismo; incluso si los europeos ya no fueran creyentes, han heredado tradiciones religiosas que transmiten riquezas espirituales, artísticas, morales que necesitan ser conocidas; la Biblia merece ocupar un puesto de honor entre las fuentes interesantes de la tradición cultural; conviene redefinir los elementos de la cultura bíblica necesarios para confeccionar un curso escolar y mostrar las implicancias éticas de sus textos; la Biblia no es propiedad exclusiva de ninguna Iglesia y permite diversas interpretaciones; al presentarla se ha de respetar la sensibilidad de creyentes y no creyentes; su contenido se puede estudiar en la escuela con una mirada simplemente histórica, lingüística o social. La cultura religiosa escolar debe combatir prejuicios sobre religión, favorecer su inserción en una sociedad sobre la base del conocimiento de sus referentes simbólicos, adquirir una visión pluralista de las experiencias humanas y de las creencias, confrontar los mitos bíblicos con los extrabíblicos antiguos y actuales, abrirse a dimensiones distintas de la razón y de la ciencia, comunicar el significado existencial de los textos sagrados. Los protestantes anhelan incluir el conocimiento bíblico en la formación de los docentes; que los estudios literarios propongan temas de los clásicos religiosos; que los programas de historia en secundaria presenten hechos religiosos; generar instrumentos didácticos para los docentes; hacer disponibles en las clases la Biblia, el Corán, antologías religiosas y monografías de tema religioso (Pajer, 2010).

4.4. La reintroducción de la religión ortodoxa en la escuela en Europa poscomunista desde los ańos 90, aprovechó que toda Europa occidental estaba en pleno esfuerzo de redefinir jurídica y epistemológicamente una enseñanza religiosa coherente con los derechos humanos, incluido el derecho a la libertad religiosa. (Barnett 2005, 211-217). Las autoridades religiosas tomaron la iniciativa de activar cursos de religión, con el consenso y hasta con la incitación popular. Pero la falta de estructuras locales para repensar críticamente el patrimonio 
religioso y para formar académicamente a los nuevos docentes postergó el inicio de una pedagogía religiosa escolar. A menudo, la didáctica escolar se ancló en la didáctica catequística parroquial. La jerarquía ortodoxa, además, mira con sospecha a la Europa occidental hipersecularizada y a su enseńanza religiosa descatequizada (Consilium Conferentiarum Episcoporum Europae, 2015).

\section{Tendencias y posibles desarrollos}

La mirada panorámica y episódica a la variada pedagogía religiosa europea muestra, por un lado, la evolución teórica de algunos conceptos base y, por otro, la transición de las prácticas didácticas hacia acomodaciones discrecionales cada vez más necesarias según los diversos sistemas educativos.

5.1. Están evolucionando la comprensión y el uso de algunos conceptos que son presupuesto y marco de toda la práctica educativa religiosa:

- el concepto de laicidad ha evolucionado desde una "arqueolaicidad" -sinónimo de indiferencia arreligiosa, de neutralidad hostil y de lucha antirreligiosa (laicismo) - hacia una "neolaicidad" o "laicidad postecular" (J. Habermas), capaz de reconocer el hecho religioso e incluso de defender los derechos a la libertad religiosa. En la escuela, esto significa pasar de una laicidad de incompetencia ("la religión no me interesa”) a una laicidad inteligente ("es derecho y deber de todos conocer el hecho religioso") (Debray, 2002).

- el concepto de libertad religiosa, entendido antes como la simple posibilidad subjetiva de creer o no creer, se amplió hasta significar hoy la promoción positiva de las condiciones previas para un ejercicio personal y comunitario de la libertad religiosa (Dignitatis humanae, 6). En la escuela, esto significa garantizar el derecho a todo ciudadano, creyente o no, a acceder al conocimiento de los hechos y problemas religiosos en vista 
de una opción libre, sobre todo si se vive en un contexto multirreligioso o agnóstico; la enseñanza religiosa, por tanto, es recurso cognitivo para orientarse con libertad de conciencia en privado y en las responsabilidades públicas.

- el propio campo semántico de la religión-que por años, incluso en la didáctica religiosa, comprendía solo la dimensión plural de las confesiones cristianas, de los monoteísmos, y de otras religiones- tiende a englobar ahora también la "no creencia" o las concepciones no religiosas del mundo; en la expresión "educación religiosa" se incluye a menudo la "iniciación a lo religioso". Además, a la omnicomprensiva "cultura religiosa" se agrega el necesario conocimiento de la "dimensión religiosa de la cultura", en las disciplinas escolares en primer lugar.

- en el ámbito social y político, la religión se piensa siempre menos como asunto privado, y cada vez más como factor insoslayable de la esfera pública. El Consejo de Europa insiste sobre las referencias normativas de la vida civil: los valores del Estado de derecho, de la democracia y de los derechos humanos, que se debilitarían si no se transmitieran a través de determinadas culturas, sean religiosas o filosóficas, y no fueran vehiculados por organizaciones dotadas de amplia base social como las Iglesias u otras comunidades creyentes.

- la percepción del rol de las Iglesias cristianas por los jóvenes ha evolucionado a tal punto que ellas no figuran como la fuente única, sino como una de las fuentes de interpretación, que habla junto a otras fuentes, también no religiosas, consideradas igualmente atendibles. Esto significa que la adhesión a una tradición religiosa, a pesar de cierta nueva ola de espiritualismo acrítico y nostálgico, no se define ya tanto por la vía de la enseñanza de la autoridad, cuanto por la vía de confrontaciones selectivas ante una oferta de verdades plurales disponibles en el mercado de lo religioso. 
5.2. Las transiciones presentes en el terreno de la didáctica religiosa ofrecen un panorama bastante diverso de datos significativos. Me limito también aquí a señalar algunas de estas transiciones:

- una vez aceptada - en el plano teórico y en sus consecuencias prácticas- la sana distinción entre catequesis comunitaria y enseñanza religiosa escolar, urge repensar a fondo los currículos de religión, refundándolos a partir de una lógica epistemológica, pedagógica y disciplinar compatible con la de los saberes escolares y de las ciencias religiosas (teológicas y no teológicas) que están en la base; de aquí la necesidad para la enseñanza religiosa de cambiar el paradigma, para proporcionar instrumentos cognoscitivos adecuados para superar comportamientos de intolerancia, y para volver a situar los símbolos, actos y mensajes religiosos en los contextos histórico-sociales de su origen y de su desarrollo.

- la bipolaridad tan discutida entre una enseñanza religiosa confesional, comprometedora de la conciencia subjetiva, y una enseñanza objetiva y neutra, se va suavizando y recomponiendo en torno a una tríada de enfoques que es necesario considerar con atención (no solo en la literatura anglosajona): learning into / about / from religion (aprender hacia el interior / acerca de / desde la religión). Tres posturas conciliables, que de hecho son estratégicamente modulables según los contextos culturales y según la edad etaria y/o creyente del alumno.

- de ser una materia a menudo aislada, casi víctima de su carácter atípico y electivo, la enseńanza religiosa llega a ser cada vez más un componente integrado en la educación escolar, que entra como disciplina paralela en asignaturas afines como la educación para la ciudadanía democrática, la educación en valores y en los derechos humanos, los estudios sociales, compartiendo sus competencias y objetivos formativos. 
- en una Europa ya sociológicamente multirreligiosa y "poscristiana", es tarea de la escuela asumir como objeto de estudio los documentos de la propia y de las demás tradiciones religiosas, y las expresiones de las culturas no religiosas, como la otra cara del mismo universo religioso: corrientes espirituales, convicciones filosóficas y éticas desvinculadas de credos religiosos, expresiones agnósticas o ateas que forman parte de la experiencia de muchos contemporáneos secularizados, adolescentes entre estos, para quienes la escuela debe poder elaborar culturalmente también estos fenómenos ya largamente difundidos e influyentes en la cultura juvenil.

- de una didáctica multirreligiosa interesada en explorar la pluralidad de las religiones, se pasa a una didáctica interreligiosa, consciente de que el problema verdadero ahora es el del pluralismo religioso (que es, al mismo tiempo, diversidad axiológica, ética, conductual): desde una curiosidad enciclopédica hacia las otras religiones, típica de los decenios pasados, se pasa a construir una identidad religiosa propia capaz de dialogar con identidades diversas.

- en el ámbito de la educación ética, superando el consabido debate coyuntural sobre problemas que ocasionalmente alimentan el show mediático de opiniones, la escuela privilegia una enseńanza ético-religiosa estructurada, que garantice el mínimo ético necesario, entendido como patrimonio de criterios de juicio y de acción, fundado en el bagaje de los derechos humanos, de las tradiciones humanísticas, de los textos sagrados de las religiones y de la historia de sus efectos, así como de la tradición religiosa de la propia historia nacional.

- el concepto de la geografía religiosa de Europa también está cambiando en el imaginario de las nuevas generaciones: crece en la didáctica escolar la relevancia geopolítica y religiosa del Mediterráneo como nuevo polo que descentra la atención de la vieja Europa de los "tres cristianismos" cristalizados en sus 
figuras históricas; la mirada se vuelca hacia un Medio Oriente agitado por el despertar polémico de los tres monoteísmos que nacieron en su cuna. Un enfoque escolar apropiado del texto bíblico (cristiano) tenderá presumiblemente a extenderse cada vez más a una confrontación necesaria con otros textos sagrados, sobre todo con el Corán, y también con el Antiguo Testamento leído más correctamente en la interpretación autónoma que hace el hebraísmo.

\section{Conclusión}

Las tendencias citadas son indicadores evidentes de que la enseñanza religiosa en Europa está en busca de un nuevo paradigma. Urge hallar nuevas legitimaciones para ella, ya que gran parte de las legitimaciones actuales se pensaron cuando Europa era un mosaico de naciones-estado y no todavía una Unión; cuando su sociedad no tenía las tasas actuales de secularización y cuando su escuela no contaba con tanta diversidad religiosa. Es necesario repensar y proyectar la educación religiosa en cuanto tal. Hay Iglesias en Europa que invierten los mejores recursos en la catequesis comunitaria, otras en la escuela pública, porque las condiciones jurídicas lo permiten y lo exigen. Unas y otras deben repensar lo "fundamental" del discurso pedagógico-religioso, porque ya son demasiado evidentes los signos del fin del modelo tridentino de trasmisión religiosa, habida cuenta de que en muchos jóvenes no está absolutamente muerto el interés por lo religioso, ni agotada la sed de nuevos valores.

Repensar hoy una pedagogía religiosa en el cuadro europeo no significa mantener el sueño de una imposible homogeneización de los modelos de didáctica religiosa. Significa, más bien, tomar nota de los profundos cambios que conmueven el contexto cultural-educativo, leer críticamente su dinámica y actuar en consecuencia. Y actuar no contra el cambio o a pesar del cambio, sino dentro del cambio. 
Flavio Pajer foc | El dilema de la enseñanza religiosa en Europa: ienseñar a CREER O A CONVIVIR?

\section{REFERENCIAS BIBLIOGRÁFICAS}

Alberts, W., ed. (2008). The History of Religions and Religious Education. Numen, LV, 2-3, 121-334.

Barnett, J., ed. (2005). A Theology for Europe. The Churches and the European Institutions. Bern, Suisse: Peter Lang.

Cano Ruiz, I., ed. (2014). La enseńanza de la religión en la escuela pública. VI Simposio internacional de derecho concordatario. Granada, España: Comares.

Catterin, M. (2013). L'insegnamento della religione nella scuola pubblica in Europa. Venezia, Italia: Marcianum Press.

Chizzoniti, A.G., ed. (2006). Organizzazioni di tendenza e formazione universitaria. Esperienze europee e mediterranee a confronto. Bologna, Italia: Mulino.

Collès, L., R. Nouailhat, eds. (2013). Croire, savoir. Quelles pédagogies européennes? Bruxelles, Belgique: Lumen Vitae.

Conferenza episcopale italiana-Servizio per l'IRC (2007). L'insegnamento della religione, risorsa per l'Europa. Ricerca delle Conferenze episcopali d'Europa. Leumann-Torino, Italia: ElleDiCi.

Consilium Conferentiarum Episcoporum Europae (2015). Religion and cultural diversity: challenges for the Christian Churches in Europe. Bologna, Italia: EDB.

Debray, R. (2002). L'enseignement du fait religieux à l'école lä̈que. Paris, France: O. Jacob.

Domingo Moratalla, A., coord. (2006). Ciudadanía, religión y educación moral. Madrid, España: PPC.

EKD (Evangelische Kirche in Deutschland) (1994), Identität und Verständigung, in Unificazione europea e insegnamento religioso, (1998), Protestantesimo, LIII, 3, 186-208.

Genre, E., F. Pajer (2005). L'Unione Europea e la sfida delle religioni. Torino, Italia: Claudiana. 
Grimmitt, M., ed. (2000). Pedagogies of RE: case studies in the research and development of good practice in RE. Great Wakering, GB: McCrimmons.

Jackson, R. et al. (2007). Religion and education in Europe. Developments, contexts, debates. Münster, Deutschland: Waxmann.

Jackson, R. (2009). The Council of Europe and education about religious diversity, British Journal of Religious Education, XXXI, 2, 85-90.

Jackson, R. (2014). Signposts. Policy and practice for teaching about religions and non-religious world views in intercultural education. Strasbourg, France: Conseil de l'Europe.

Keast, J., ed. (2007). Religious diversity and intercultural education: a reference book for schools. Strasbourg, France: Council of Europe.

Kuyk, E. et al., eds. (2007). Religious Education in Europe. Situation and current trends. Oslo, Norway: Iko Publishing.

Messner, F. ed. (2010). Droit des Religions. Dictionnaire. Paris, France: CNRS.

OSCE-ODIHR (2007). Toledo guiding principles on teaching about religions and beliefs in public schools. http://osce.org/ odhir/29154https://www.osce.org/odihr/29154?download=true.

Pajer, F. ed. (1991). L'insegnamento scolastico della religione nella nuova Europa. Leumann-Torino, Italia: ElleDiCi.

--.---- (2007). L'istruzione religiosa nella costruzione dell'Europa, Pedagogia e Vita, LXV (3-4), 44-61.

-------- (2008). Educación religiosa y educación para la ciudadanía: ¿instrumentalización recíproca o papeles específicos? Diálogo Filosófico, XXIV (3), 429-454.

-------- (2010), In Francia, l'insegnamento laico del fatto religioso, Pedagogia e Vita, LXVIII, 3-4, 14-37.

(2012). Toward a post-secular Europe. Regulating religious diversity in the public space. Historia Religionum, IV (4), 11-121. 
Flavio Pajer fsc | El dilema de la enseñanza religiosa en Europa: ienseñar a CREER O A CONVIVIR?

(2015), Cómo y por qué Europa enseña las religiones en la escuela: los tres paradigmas. Revista electrónica de Educación Religiosa, V (1), 1-24: http://www.reer.cl/index.php/reer/article/ view/40/40.

------- (2017). Dio in programma. Scuola e religioni nell'Europa unita. Brescia, Italia: Morcelliana.

- (2019). Religious rights, educational duties? in: Melloni, A., Cadeddu, F., eds. Religious Literacy, Law and History. LondonNew York: Routledge, 46-66.

Parisi, M. (2005). Le organizzazioni religiose nel processo costituente europeo. Napoli, Italia: Edizioni Scientifiche Italiane.

Pépin, L. (2009). L'enseignement relatif aux religions dans les systèmes scolaires européens. Bruxelles, Belgique: NEF.

Porzelt, B. (2014). Nuove pubblicazioni e sviluppi nella pedagogia religiosa tedesca, Itinerarium, XII, 67-93.

Robbers, G. (20042). Stato e Chiesa nell'Unione Europea. Milano, Italia: Giuffrè.

Rusconi, R., ed. (2012). Insegnare a credere. Costruzione degli Stati nazionali e insegnamento della religione nell'Europa contemporanea. Rivista di Storia del Cristianesimo, IX (1),3-160.

Stagi P. (2017). L'Europa e le Religioni. Roma, Italia: Castelvecchi.

Willaime, J.-P., S. Mathieu, eds. (2005). Des maîtres et des dieux. Écoles et religions en Europe. St-Etienne, France: Belin.

Fecha de recepción: 30 de abril de 2019 Fecha de aceptación: 23 de mayo de 2019 